\title{
Reclutamiento militar, articulación política y mecanismos de clase en el Alto Valle del Ebro durante el siglo XVII. El Concejo de Calahorra
}

\author{
JULIO LUIS ARROYO VOZMEDIANO* \\ UNED \\ Army recruitment, political juncture and class mechanisms in the \\ High Valley of the Ebro river \\ during the $17^{\text {th }}$ Century. The City Council of Calahorra
}

\begin{abstract}
RESUMEN
El propósito del autor es tratar de elucidar los procedimientos y mecanismos con los que se articulaba la relación entre el poder central de la monarquía hispana y los centros periféricos, en este caso el de

la ciudad de Calahorra y sus anejos. A través del estudio de diversos expedientes de levas y reclutas producidas en la ciudad durante el siglo XVII, con oportunidad de las diversas guerras con Francia, se estudian sus procedimientos, su ejecución y las repercusiones que en los distintos grupos sociales causaban aquéllas.
\end{abstract}

PALABRAS CLAVE: Ejército / siglo XVII / levas / Calahorra / historia social

\begin{abstract}
The aim of the author is to clarify the procedures and mechanisms with which the relations between the central power of the Hispanic monarchy and the peripheral centers were articulated, dealing with the case of Calahorra. Through the study of diverse files of levies and recruits produced in the city during the 17th Century, in the occasion of the diverse wars against France, their procedures, their execution and the repercussions caused in the different social groups are analysed here.
\end{abstract}

KEYWORDS:

Army / 17th Century / recruitment / City of Calahorra / social history

* Becario FPI, adscrito al Proyecto Guerras de España. Identidad y política en la encrucijada de 1700. Depto. Historia Moderna. UNED. Senda del Rey, 7. 28040 - Madrid. e-mail: superjulio@ telefonica.net 


\section{INTRODUCCIÓN}

Existe una crisis durante el s. XVII en los territorios de la Corona de Castilla, este fenómeno, que no afecta por igual a cada una de las partes de dichos territorios, es originado, en gran medida, por las decisiones políticas y económicas de la Corona. Sus procesos, mecanismos y consecuencias han sido estudiados ampliamente por la historiografía. Sus análisis y explicaciones a aquella ofrecen un alto grado de coincidencia: guerras, alta presión fiscal, recesión demográfica, crisis productiva e inflación. Dicha crisis debe de tener su natural reflejo en la articulación política del territorio y producir una lógica modificación de sus mecanismos.

Durante el siglo XVII, y en el tiempo de las guerras europeas de los llamados Austrias Menores se asiste, en un contexto de dificultad, a la transformación de los sistemas de reclutamiento y leva de contingentes militares ${ }^{1}$. Detrás de todo ésto subyacen los cambios experimentados en el arte de la guerra durante los siglos modernos, donde cada vez se dan cita en los campos de batalla ejércitos más y más numerosos y, naturalmente, más caros. También se produce una multiplicación de los teatros de operaciones y de las obligaciones a atender por los distintos Estados, asunto especialmente preocupante en la España de los Austrias debido a su muy extenso despliegue estratégico que en el siglo debe enfrentar operaciones militares en Asia, África, América y, por supuesto, en Europa.

Las obligaciones, por tanto, superan cada vez en mayor medida a las posibilidades y a los recursos con que cuenta la Monarquía Hispánica para hacerles frente, amén de la carga de intereses y obligaciones que gravaban la situación, herencia de conflictos prácticamente ininterrumpidos desde tiempos de Carlos I. Y así es como Olivares en 1640, con ocasión de la revuelta e invasión francesa en Cataluña y con los ejércitos en Flandes, ordena el recurrir a formulas medievales para hacer frente a la situación ${ }^{2}$. Se intenta resucitar el concepto del ejército feudal y se recurre a las milicias ciudadanas, ya previstas en la unión de armas.

Calahorra gozaba del privilegio de exención de participar en las milicias ${ }^{3}$, pero, como recuerda el Conde de la Coruña, virrey de Navarra, al concejo de la ciudad en 1642: «[...] en las ocassiones de Invasión en esse Reyno [por Navarra]

1 SIMÓN TARRÉS, Antonio: «La política exterior», en DOMÍNGUEZ ORTIZ, Antonio (dir): La crisis del siglo XVII. Historia de España, Planeta, Barcelona, 1988, t. VI, pp. 335-446, en p. 379: «[...] las dificultades demográficas generalizadas y el incremento de la actividad bélica de la monarquía determinaron una serie de transformaciones importantes en los sistemas de reclutamiento cuyas consecuencias principales fueron: el encarecimiento del sistema de asiento, la reducción - a veces desaparición- del carácter voluntario de los enganches. Desde 1620 se empleó la coacción para obligar al servicio [...]. Asimismo, desde 1635, la monarquía, en un supremo intento de conseguir hombres, trató sin demasiado éxito de resucitar las obligaciones del servicio feudal para la nobleza y del servicio militar para el resto de la población».

2 LYNCH, John: Los Austrias, Crítica, Barcelona, 2003, p. 534.

3 Ver SAMANIEGO MARTÍ, M. ${ }^{a}$ Carmen: «El servicio de milicias en el siglo XVII: Un privilegio de exención en Logroño, Calahorra y Alfaro", Actas del Segundo Coloquio sobre Historia de La Rioja. Logroño, 1986, Vol. 2, 1986, pp. 225-236. 
Reclutamiento militar, articulación política y mecanismos de clase en el Alto Valle del...

tiene obligación de dar la ciudad de calaorra cien infantes y assi se le escribe que al primer avisso que tuviere nuestro o del Consejo de Cantabria ${ }^{4}$ marche con esta infantería como en otras occassiones lo ha executado y que desde luego la tenga prompta y abilitada en el manejo de las armas ${ }^{5}$.

Así, y al amparo de este precepto, se producen, durante el siglo XVII, varias levas destinadas al reforzamiento de los presidios fronterizos con los estados del Rey Sol. Mediante el estudio de las levas realizadas en los años de 1644, 1655, 1667 y 1668, escudriñaremos los cambios que se producen en las relaciones entre el concejo y la monarquía. Asimismo la documentación ofrecerá una imagen fiel de los distintos estadios sucesivos que se van produciendo a lo largo del periodo de 24 años que separan la primera y la última de las reclutas tratadas. Este corte diacrónico ofrecerá la oportuna perspectiva dinámica necesaria para rastrear la evolución histórica en aspectos militares, políticos y sociales.

\section{LOS CONFLICTOS}

El instrumento fundamental de la política exterior de los estados modernos fue la guerra. El esfuerzo militar tuvo un doble efecto, por una parte se sitúa en el origen de los estados nacionales y por otra parte permitió que las dinastías reinantes se mantuvieran por encima del resto de los magnates de sus reinos ${ }^{6}$. El proceso no es idéntico, como es natural, en los diversos estados de la época. En la Inglaterra de la guerra civil y como uno de los factores desencadenantes de la misma, se sitúa el intento de Carlos II Estuardo de establecer un impuesto permanente, al estilo de la Taille francesa, que le permitiera disponer de un ejercito profesional al estilo de los estados continentales, la resistencia al mismo del Parlamento y su ulterior victoria truncan el proceso y explica la singular evolución posterior de las Islas Británicas.

En dicho contexto, durante la Alta Edad Moderna se produce una concatenación de conflictos, entre cuyas motivaciones estratégicas fundamentales se encuentra la pugna por la hegemonía continental entre las monarquías francesa e hispánica. Esta lucha tiene un primer desenlace en la guerra de los Treinta Años y en la continuación del conflicto franco-español al final de aquella, del que resulta el fracaso del intento hegemónico español. Con posterioridad a la Paz de los Pirineos

\footnotetext{
${ }^{4}$ Este consejo de Cantabria parece relacionado con el visigótico ducado de Cantabria, que se encuentra en la génesis histórica de la diócesis de Calahorra-La Calzada. Esta diócesis abarcaba durante la Edad Moderna las actuales provincias de La Rioja, Álava, Bilbao y zonas de Guipúzcoa, Burgos, Navarra y Soria. Esta situación permanecería hasta el concordato de 1851. Para esta cuestión ver GRANADO HIJELMO, Ignacio: “Calahorra y el sistema riojano en los Siglos de Oro», en Kalakoricos, $n^{\circ} 6$ (2001), pp. 171-200.

5 Archivo Municipal de Calahorra (en adelante, AMC), signatura 50016, serie 2.1.5.7.

6 Ver KENNEDY, Paul M.: Auge y caída de las grandes potencias, Plaza \& Janés, Barcelona, 1994. En las pp. 127-131, desarrolla este argumento: «[...] lo que ejerció una más continua y apremiante presión a favor de la «construcción de la Nación» fue la guerra y sus consecuencias».
} 
se produce la tentativa francesa por la supremacía continental en cuyo contexto se reanudan las luchas con su vecino del sur hasta que las especiales características que rodearon la sucesión de Carlos II, marcan el final de las contiendas y la reordenación general de la política exterior europea que supone Utrecht.

La participación francesa en la guerra de los Treinta Años, largamente pensada por Richelieu, se produce a partir de 1635 y decide llevar la misma al mismo territorio de su rival. Esta intervención se produce en los extremos oriental y occidental de los Pirineos. Quizá animado por los sucesos de principios de la década $^{7}$ y pensando en la misma combinación que dos años más tarde le daría buenos frutos en Cataluña, se decide el ataque a la Península en el lugar de Fuenterrabía. En 1638 un ejército al mando del Príncipe de Condé penetra en España y pone sitio a Fuenterrabía. La tentativa fracasa, ya que la enconada defensa que los moradores de la villa guipuzcoana ofrecieron a sus atacantes permitió la llegada de tropas en auxilio de la desde entonces ciudad ${ }^{8}$. La victoria obtenida y las circunstancias en que se obtuvo, tuvieron una amplia repercusión en la Corte. Se produjo una amplia literatura ${ }^{9}$ acerca de aquella, siendo la más notable la obra de Juan de Palafox y Mendoza, por encargo del propio Felipe IV. EI propio Manuel de Melo relata estos sucesos y los sitúa en los antecedentes de la guerra de Cataluña: «No tardó mucho el exército Cristianísimo en dar vista á la provincia de Guipúzcoa, gobernado por Henrique de Borbón, Príncipe de Condé (hombre en todos tiempos mas esclarecido que afortunado): pasó los linderos de la Francia con poderosa mano, á la que obedecían hasta veinte mil combatientes. Viendo España entonces las lises de sangre, que ya la antigua paz y deudo habían vuelto de oro, sitió á Fuente Rabía, plaza de opinión en la Cantabria, y después de un riguroso asedio perdió la empresa, el poder y los intentos, habiéndola socorrido (contra toda esperanza) los exércitos de D. Juan Alonso Henríquez de Cabrera, Almirante de Castilla, y de D. Pedro Faxardo de Zúñiga y Requesens, Marques de los Vélez, por la industria de Carlos Caraciolo, Marques de Torrecusa, su Maestre de Campo genera/10».

7 ELLIOTT, John Huxtable: «Los disturbios de Vizcaya (1631-1634)», en JOVER ZAMORA, José María (dir.): La España de Felipe IV. Historia de España, Espasa Calpe, Barcelona: 1982, t. XXV, pp. 427436.

${ }^{8}$ Felipe IV, a raíz de estos sucesos le concedió el titulo de ciudad y una asignación a los defensores, hombres y mujeres. Desde entonces Fuenterrabía celebra en conmemoración el llamado «alarde», últimamente tan polémico.

9 Por citar sólo alguno de los numerosos panfletos y obras, apuntaremos el del jesuita pamplonés MORET, Juan: Empeños del valor, y bizarros desempeños o sitio de Fuenterrabía, Pamplona, 1654; el opúsculo de ASPILIQUETA, Martín de: Relación de todo lo sucedido en Fuenterrabía desde que el príncipe de Condè la puso en sitio, hasta que se retiro con afrentosa huida, Bilbao, 1638; y la del impresor riojano MARES, Matías: Relación verdadera del socorro que a Fuenterrabía dieron los excelentíssimos Almirante de Castilla y Marqués de los Vélez, Virrey de Navarra, Generales de ambas coronas en esta facción, víspera de Nuestra Señora de Setiembre, Logroño, 1638.

10 MANUEL DE MELO, Francisco: Historia de los movimientos, separación y guerra de Cataluña, en tiempo de Felipe IV, Imp. Hernando, Madrid, 1645 [Biblioteca Virtual Miguel de Cervantes, Alicante, 1999, c. 1, epígrafe 18] 


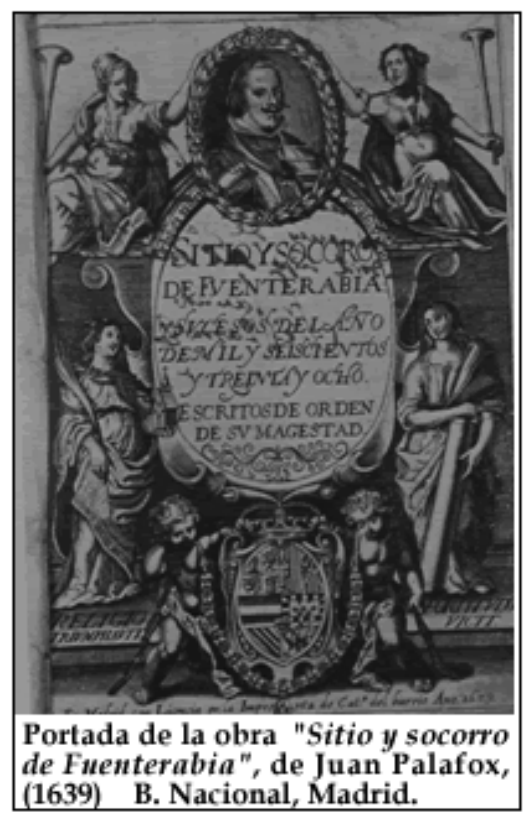

Fig. 1. BNE, 2/51275. Juan de Palafox: Sitio y socoro de Fuenterabía y sucesos del año de mil seiscientos y treinta ocho ...

Y a modo de resumen como continua el propio Manuel de Melo «En este estado se hallaban los negocios de la guerra interior de España al fin del año de seiscientos treinta y ocho (el que entre todos pudo llamar dichoso aquella monarquía); pero aunque sus armas triunfasen victoriosas, érales imposible poder cubrir $y$ asegurar las provincias distantes ${ }^{11}$ ».

Quizás la consecuencia fundamental de los sucesos de Fuenterrabía fue la toma de conciencia de la vulnerabilidad estratégica de las plazas fuertes guipuzcoanas: su posible control por parte de los franceses les dejaría expedito el paso a los puertos cantábricos, a Navarra, al valle del Ebro e, incluso, a la submeseta norte a través de La Bureba, siendo por tanto más potencialmente peligrosos que los sucesos de Cataluña, al fin y al cabo, en una situación más periférica.

Por tanto, se produce un temor constante a nuevos intentos franceses a través de las plazas de Guipúzcoa. Estos intentos no se volvieron a sustanciar en asedios de Fuenterrabía hasta el s. XVIII pero constituyeron una preocupación táctica para la Corona Hispánica y tuvieron, como veremos, consecuencias para los habitantes de la Calahorra del s. XVII'12.

11 MANUEL DE MELO, Francisco: Historia de los movimientos ..., c. 1, epígrafe 19.

12 Las levas no sólo están documentadas con destino a Fuenterrabía, sino que también lo están para otros puntos del norte peninsular, por ejemplo, véase SANCHEZ BELEN, Juan Antonio: «La aportación 


\section{LEVAS EN CALAHORRA}

Como hemos explicado, la situación en los años centrales del s. XVII era tal que se recurría a cualquier expediente a la hora de recabar los medios necesarios para la salvaguardia del reino. Amparándose en la tradicional de defensa de Navarra a que estaban obligados los calagurritanos, las autoridades de la Monarquía Hispánica, solicitaron en diversas ocasiones su auxilio para reforzar las guarniciones de los presidios de Navarra y Guipúzcoa.

Ésto responde bastante bien a la lógica geográfica. Dada la situación de la ciudad riojana, parece natural la exigencia de defender precisamente aquellos territorios que, por ser cercanos y fronterizos con el enemigo francés, su vigilancia es también un resguardo de la propia ciudad, ya que es de donde potencialmente podrían venir los riesgos más probables.

Por otra parte, debemos señalar que al referirnos a Calahorra en este trabajo debemos de tener en cuenta que su ámbito abarca también a otras poblaciones jurídicamente dependientes de ella como son Aldeanueva de Ebro, Murillo de Calahorra y Rincón de Soto.

En los expedientes que recoge el presente estudio normalmente el destino de los reclutas era el presidio de Fuenterrabía que, si bien no se encuentra en Navarra, parece ajustarse al precepto invocado, como se desprende de las palabras del Conde de Oropesa en carta a la ciudad de Calahorra el 4 de febrero de $1644^{13}$ : «siendo esta plaza la que por Guipúzcoa cubre a Navarra», parece ajustarse al principio invocado.

En el Archivo Municipal de Calahorra se conservan, en buen estado, cuatro expedientes correspondientes a otras cuatro reclutas realizadas en los años de $1644,1655,1667$ y $1668^{14}$, siendo las tres primeras levas forzosas de naturales y la última una recluta de voluntarios con cargo a la Hacienda Real. La información que recoge estos expedientes varía de unos a otros aunque presenta ciertas uniformidades que permiten reconstruir el procedimiento y distinguir sus momentos procesales:

de la provincia de Álava a la contienda hispano-portuguesa en los años finales del reinado de Felipe IV (1663-1665)", en Espacio Tiempo y Forma, Serie IV, nº 12 (1999), pp. 249-274, (la referencia en p. 256). El autor refiere una leva en Álava en septiembre de 1665 con destino a reforzar el presidio de Fuenterrabía.

${ }^{13}$ AMC, sign. 458002 , serie 2.1.5.2.

14 Los expedientes que contienen las fuentes son:

\begin{tabular}{|c|c|c|}
\hline Leva & Signatura legajo & \multirow{5}{*}{$\begin{array}{l}\text { Todas las citas del contenido } \\
\text { se entienden referidas a las } \\
\text { signaturas aquí expresadas } \\
\text { en función del año de la } \\
\text { recluta }\end{array}$} \\
\hline 1644 & AMC, sig. 458002 , serie 2.1 .5 .2 & \\
\hline 1655 & AMC, sig. 458003 , serie 2.1 .5 .2 & \\
\hline 1667 & AMC, sig. 458005 , serie 2.1 .5 .2 & \\
\hline 1668 & AMC, sig. 458007 , serie 2.1 .5 .2 & \\
\hline
\end{tabular}


Reclutamiento militar, articulación política y mecanismos de clase en el Alto Valle del...

a. Los reclutamientos se inician con un requerimiento o instrucción motivada a la ciudad para que efectúe el reclutamiento. Esta instrucción puede tener diversas formas y órganos emisores, aunque siempre se trata de oficiales del Rey (o el Rey mismo). Este requerimiento a su vez puede reiterarse en caso de retraso de la ciudad en obedecer las órdenes.

b. Se reúne el concejo quien procede al reparto de la carga entre el núcleo principal y sus pedanías.

c. Luego de ésto se produce la saca de soldados que genera una lista con los nombrados para tal menester.

d. Se abre un plazo, en el que se pueden producir alegaciones de los mozos y sus familiares, que termina con la entrega de soldados y partida para su destino. En su caso se produce también el nombramiento de oficiales.

e. En otra reunión del concejo ciudadano se aprueban las cuentas, ya que la leva se efectúa con cargo a la ciudad.

f. Y por ultimo, también en concejo público se hace el repartimiento de los gastos entre vecinos y se liquidan las cuentas, lo que acaba el procedimiento.

Estos pasos se pueden agrupar, como veremos en algún supuesto, y también varían los plazos y procedimientos cautelares para asegurar la presentación de los soldados, aunque en cualquier caso la secuencia es similar en todos los casos.

\subsection{Leva de 1644. Reclutamiento de 50 infantes con destino al presidio de Fuenterrabía.}

Este procedimiento se inicia por parte del Condestable de Castilla, quien en carta fechada el 28 de enero de 1644, traslada la orden real de que los corregimientos de Logroño, Alfaro y Calahorra, recluten 200 de los 400 infantes con que están obligados a socorrer al reino de Navarra. La carta motiva su petición así: «[...] con la mayor brevedad que sea posible y que importa por los avisos que ay de que el enemigo quiere hazer invasión en aquella plaza y del reyno [...].

Tras ésto, se suceden varias misivas nuevas por parte del mismo autor y del virrey de Navarra, conde de Oropesa, en las que reclaman el cumplimiento de las órdenes. Tienen razon en sus quejas: "siendo imposible haber dexado de llegar a vos [las instrucciones]». La conservación de las mismas en el Archivo Municipal es prueba de ello, sin embargo no parece que tengan el efecto deseado. El propio Felipe IV se dirige directamente a la ciudad el 15 de marzo desde Zaragoza:

«El Rey. Concejo, Justicia, Regidores, Cavalleros, Escuderos, oficiales y hombres buenos de la Ciudad de Calahorra. La gente que os escrivio el Condestable de Castilla pusiesedes en Fuente Rabia hace gran falta para la seguridad y defensa de aquella plaza y si vien espero que quando esta llegue habreis remitido lo 
que se os a pedido para el dicho efecto, he querido encarguaros que en casso de que no haya partido la enbieis sin dilacion alguna, según y en la forma que os lo ha avisado el condestable, estando cierto que todo lo que obradareis en esta diligencia sera igual a la confianza con que estoy de la demostración y fineza con que acudis a lo que estando a mi servicio y que en esto recivire de vos, de Zaragoza a 15 de Marzo del 1644. Yo el Rey. A la ciudad de Calahorra para que envie a Fuenterrabía la gente que se le ha pedido»

La real cédula tiene efectos inmediatos, el día 21 de marzo el concejo de Calahorra efectúa el reparto entre los núcleos y nombramiento de soldados de la propia ciudad. Nombrándose los de Aldeanueva y Rincón de Soto el 28 y los de Murillo el 6 de abril.

Se abre un plazo de indefinición, salpicándose el expediente de cartas de oficiales del Rey y de embargos de los bienes de los nombrados, pero que no concluyen en la partida reclamada. Esta espera se precipita el día 20 de mayo en que el corregidor Pedro Garcia de Jalón ordena "que prendan los que ansi estan nombrados en esos lugares [...] de no poder ser avidos los nombrados se prendan a sus hermanos o padres y los remitan a la carcel real de esta ciudad y se cumplan ansi pena de cincuenta mil maravedíes para gastos de guerra y de los daños a su majestad». Estas medidas surten sus efectos y el día 31 de mayo se produce la partida de los soldados. La medida del encarcelamiento se demostró eficaz y se tornaría en un elemento característico, a partir de aquí.

Terminamos señalando que en las fuentes consultadas no se conserva documentación económica, ni cuentas de gastos, ni repartimientos.

CUADRO 1. Relación de los infantes que marchan a Fuenterrabía (31 mayo 1654).

\begin{tabular}{|l|c|l|c|}
\hline \multicolumn{1}{|c|}{ Nombre } & Edad & \multicolumn{1}{c|}{ Nombre } & Edad \\
\hline Calahorra & & Rincón de Soto & \\
\hline Francisco de Miranda & 20 & Felix de leza & 25 \\
\hline Juan Lopez de Vaguedano & 40 & Pedro del Prado & 20 \\
\hline Francisco de Leza & 20 & Pedro Palacios & 20 \\
\hline Juan de Burgos & 30 & Pedro de Muro & 20 \\
\hline Celedón de Vidijalbo (por su hijo) & - & Matias Adan & 20 \\
\hline Diego Cano & 40 & Aldeanueba & 18 \\
\hline Pedro Diaz & 24 & Miguel Mateo & 20 \\
\hline Joan Moya & 20 & Martín Perez & 20 \\
\hline Joan Moreno & 28 & Domingo Perez & 23 \\
\hline Pedro del Rey & 18 & Joan Garrido & \\
\hline
\end{tabular}


Reclutamiento militar, articulación política y mecanismos de clase en el Alto Valle del...

\begin{tabular}{|c|c|c|c|}
\hline Nombre & Edad & Nombre & Edad \\
\hline Calahorra & & Aldeanueba & \\
\hline Juan Varres & 26 & Martin Perez & 40 \\
\hline Francisco de Aguirre & 18 & Bartolomé Ortega (por su hijo) & - \\
\hline Alonso Munilla (por su hijo) & - & Joan de Soldevilla (por su hijo) & - \\
\hline Juan de Vergara & 18 & Domingo Perez & 20 \\
\hline Gaspar de Aguirre & 40 & Lazaro de Ocon & 28 \\
\hline Josef Pascual & 22 & Antonio Rodríguez & 26 \\
\hline Francisco Sanchez & 20 & Diego Duarte & 24 \\
\hline Domingo de Ripalta & 29 & Miguel Gutierrez & 20 \\
\hline Joseph Jil & - & Domingo de Vidijalbo & 20 \\
\hline Pedro Ruvio & - & Pedro Ruiz (por su hijo) & - \\
\hline Josef de Antoñanzas & - & \multicolumn{2}{|l|}{ Murillo } \\
\hline Diego de Peza & - & Domingo Xil (por su hijo) & - \\
\hline \multirow[t]{3}{*}{ Pedro de Trevijano } & 19 & Domingo Pellejero & - \\
\hline & & Juan de Peñalva & - \\
\hline & & Mathias Sainz & - \\
\hline
\end{tabular}

Fuente: Elaboración propia a partir de AMC, sig. 458002, serie 2.1.5.7.

\subsection{Leva de 1655. Reclutamiento de 30 infantes con destino al presidio de Fuenterrabía.}

Este procedimiento tiene un antecedente en una real cedula de 15 de enero en el que se encarga una recluta de cien infantes destinados al ejercito de Cataluña al corregidor de Logroño, Alfaro y Calahorra. Ésto, sin embargo, no parece obrar efectos, ya que no se conservan ni posteriores reclamaciones, ni reparto desde Logroño, ni diligencias efectuadas por parte de los regidores calagurritanos. Todo ello se debe probablemente a que desde dos años antes la situación en Cataluña es más tranquilizadora e, incluso, el cambio general de la política europea tras el fin de la guerra de los Treinta Años, que anticipan el final del conflicto con el reino Francés.

En sí, la recluta tiene su origen en la orden que, el 24 de octubre de 1655, dirige el corregidor de Logroño y en la que se da cuenta de un cambio de instrucciones de su majestad, para que en vez de acudir a Cataluña, se refuercen, con el contingente previsto, los presidios guipuzcoanos. En el expediente se conserva una copia de la Real Cedula que ordena el cambio. La misma detalla la situación en las Plazas de San Sebastián y Fuenterrabía, donde hay escasez de soldados y no se 
podrán hacer los relevos de las guardias cuando partan de sus puertos las naves de la armada allí atracadas. En la misma se comunica el repartimiento, 30 soldados a Calahorra y las condiciones de la leva. Los soldados deberán ir provistos de espadas y vestidos de munición así como deberá abonárseles su soldada hasta la llegada a destino, todo ello por cuenta de la Ciudad.

Los regidores de Calahorra se reúnen en concejo el 11 de noviembre y en el mismo acuerdan el repartimiento correspondiendo quince mozos a Calahorra y quince a sus anejos. Esta vez directamente se apresa a los sacados y se les mete en la cárcel a la espera de su partida.

Aquí es cuando deben de realizarse las reclamaciones, transcribimos una de ellas, por su utilidad para describir el material humano del que se nutría la leva:

«Juan Aldea, morador en lugar de Murillo de esta jurisdicción, como mas digo que para la leva presente de soldados con que se sirve a su majestad, el alcalde y rexidor del dicho lugar an prendido a Francisco Aldea, mi hixo, para que vaya por tal soldado y esta preso en la carcel de esta ciudad. Y de justicia vuestra merced sea de servir se le mande soltar della libremente, mandando que el dicho alcalde y rexidor nombre otro en su lugar que aga el dicho servicio. Asi lo pido y se debe hacer asi lo primero por lo xeneral, lo otro por que las hordenes y cedulas reales de su majestad ablan en razon de los nombramientos de los soldados, disponen que ninguno pueda ser nombrado ni compelido a yr soldado a menos que tengalos diecisiete años cumplidos, y el dicho mi hixo no los tiene ni cumple asta diecinuebe de Abril del año que biene de mil y seiscientos y cincuenta y seis como consta de esta fe de bautismo que presento, dada por el cura de la Iglesia del dicho lugar en forma debida y con el juramento necesario. Y por que soy un hombre muy pobre y necesitado y con muxer y hixo, sin acienda ninguna y que los sustento de mi sudor y trabaxo y que en el dicho lugar ay otros moços que no tienen las dichas excepciones. Por tanto a Vmd. Pido y suplico le mande dar por libre y soltar de dicha prision dandole por libre y quel dicho alcalde y rexidor nombre otro en su lugar, pido justicia y costas para ello».

No es la única, se conservan cuatro reclamaciones más:

CUADRO 2. Reclamaciones de la leva de 1655

\begin{tabular}{|l|l|c|}
\hline \multicolumn{1}{|c|}{ Nombre } & \multicolumn{1}{|c|}{ Alegación } & En lista final \\
\hline Medel Ruiz & $\begin{array}{l}\text { Soldado licenciado de la compañía de Don Diego de } \\
\text { Cuellar, alférez y gobernador de una compañía de in- } \\
\text { fantería española en Flandes. }\end{array}$ & Sí \\
\hline Tomas Ortiz & $\begin{array}{l}\text { Natural de la jurisdicción de Villar y no corresponderle al } \\
\text { no ser del lugar. }\end{array}$ & No \\
\hline Francisco Aldea & $\begin{array}{l}\text { Por no tener la edad precisa para el reclutamiento como } \\
\text { soldado }\end{array}$ & Sí \\
\hline
\end{tabular}


Reclutamiento militar, articulación política y mecanismos de clase en el Alto Valle del...

\begin{tabular}{|l|l|c|}
\hline \multicolumn{1}{|c|}{ Nombre } & \multicolumn{1}{|c|}{ Alegación } & En lista final \\
\hline $\begin{array}{l}\text { Pedro Perez } \\
\text { de Adan }\end{array}$ & $\begin{array}{l}\text { Por haber servido en la ciudadela de Pamplona, haber } \\
\text { enfermado y, a su cargo, haber colocado a otro soldado } \\
\text { en su lugar. }\end{array}$ & No \\
\hline
\end{tabular}

Fuente: Elaboración propia a partir de AMC, sig. 458003, serie 2.1.5.2. destino:

El quince de noviembre se redacta la lista de soldados que deberán partir a su

CUADRO 3. Relación de infantes de 1655

\begin{tabular}{|c|c|c|c|}
\hline Nombre & Edad & Nombre & Edad \\
\hline Calahorra & & Rincón de Soto & \\
\hline Juan de Baylos & 20 & Diego Escudero & 18 \\
\hline Francisco Ernandez & 40 & Manuel Perez & 20 \\
\hline Francisco Alonso & 17 & Miguel Palacio & 22 \\
\hline Domingo Bermejo & 18 & Juan de la Questa & 21 \\
\hline Meterio Ochoa & 19 & \multicolumn{2}{|l|}{ Aldeanueba } \\
\hline Juan Fernandez & - & Manuel Fuentes & 17 \\
\hline Juan de Castro & - & Medel Ruiz & 24 \\
\hline Juan Pardo & 20 & Francisco Gutierrez de Bidijalno & 17 \\
\hline Pedro García de Torre & 17 & Pablo de Guevara & 22 \\
\hline Isidro Vallero & 34 & Pedro de Arnedo & 31 \\
\hline Celedón de Antoñanzas & 25 & Juan Cordon & 17 \\
\hline Juan de Medina & 30 & Francisco Gonzalez Cabello & 31 \\
\hline Sebastián Saenz & 17 & Joseph de Soto & 20 \\
\hline Diego Pedruelo & 18 & \multicolumn{2}{|l|}{ Murillo } \\
\hline \multirow[t]{3}{*}{ Juan de Bidijalno } & 26 & Pedro de Ravanera & 20 \\
\hline & & Francisco Aldea & 17 \\
\hline & & Diego del Rey & - \\
\hline
\end{tabular}

Fuente: Elaboración propia, AMC, sig. 458003, serie 2.1.5.2.

La fecha exacta de la partida de los infantes no aparece reflejada en las fuentes, pero ésta no puede ser posterior al 26 de noviembre en que el Corregidor escribe desde Logroño al concejo calagurritano «[...] para dar a VS las gracias de la 
firmeza y la puntualidad en que an obrado en esta leba me faltan las palabras pero me sobra el conocimiento».

Por último se liquidan las cuentas, las referidas a Calahorra, no incluyendo las de los núcleos. Así, el 1 de diciembre se hace la relación con detalle de gastos de la leva por 2.222 reales. Al día siguiente se procede al repartimiento del importe entre los vecinos por un cargo total de 2.392 reales y el 20 de febrero del año siguiente Juan de Olivan, quien se adjudicó el repartimiento, liquida las cuentas y concluye el proceso y el expediente.

El análisis de la documentación muestra muchos puntos curiosos en las cuentas que se aprueban, aparte del descuadre que se asigna a quiebras. Por un lado, existe un grupo de cinco vecinos que adelantan 2.200 reales y por los que aparentemente no obtienen ganancias. Por otro, aparecen pagos a suministradores del vestido y armamento por un total de 2.199 reales (aquí se incluyen los pueblos). Sin embargo no aparecen los nombres de los proveedores, solo aparecen las cantidades. Asimismo, la cantidad que percibe el repartidor, 250 reales, ya parece elevada pero lo realmente extraño es la cantidad cobrada por el escribano, 150 reales, que no corresponden a ningún tipo de riesgo financiero y está fuera de proporción. Finalmente, se puede constatar la aparición de una serie de oficios que se benefician económicamente del expediente, si bien en cantidades pequeñas pero que conforman una especie de burocracia de servicios: al alcaide le corresponden 30 reales, a los alguaciles 12 reales, a 11 repartidores 2 reales, y a varios oficios más, como los correos a Logroño, los muleros, etc.

\section{3. Leva de 1667. 50 infantes, un alférez y un sargento para sostener el presidio de la ciudadela de Pamplona.}

"Con ocasión de hallarse franceses con numero considerable de gente y la armada desocupada se puede temer que quieran invadir este reyno o alguna de las plazas de la provincia de Guipúzcoa», asi empieza el Virrey de Navarra, duque de San Germán, su carta de 5 de agosto de 1667 a D. Joseph de Nobar, corregidor de Logroño para invocar la sempiterna leva en auxilio de sus posiciones.

Sin dilación, el corregidor escribe a Calahorra el 6 de agosto y dos días después se hace el repartimiento. Los regidores de Calahorra no se lo piensan, tal y como se recoge en un oficio del 9 de agosto de 1668 «[...] en razón del servicio de los cincuenta infantes para el presidio de la ciudadela de Pamplona la noche última pasada, haviendo asistido por sus personas y ministros toda la noche por las eras, puertas, molinos y campos desta ciudad y el presente dia asi presos y puestos en la carcel Real de ella [por Calahorra] y entregados a Diego de Tejada, su alcayde, a Joseph de Nobadilla, Simon Fernandez, Francisco Villodas, Joseph Gonzalez Merino, Bernabé Romeo, Miguel Ruiz, Joseph de la Torre, Domingo de las Heras Menci, Joseph Ximenez, Juan Miguel, Juan de Caseda, Francisco Benito, Blas Serban, Lucas Cubilla, Francisco Soriano, Francisco Garcia, Juan Cetina [...]”. 
La urgencia del procedimiento y la nocturnidad con que se llevó a cabo parecen diseñadas para evitar el alejamiento de los mozos al tener noticias de la leva en curso. La implacabilidad y el cuidado extremo en asegurar el éxito de la leva son muestra de una identificación de intereses con la Corona por parte de las autoridades municipales. En este determinado momento histórico, coincidente con la regencia de la Reina Gobernadora, no se demuestra un debilitamiento del poder central sino que se ha producido un reforzamiento del mismo respecto a los tiempos de Felipe IV.

Una vez realizados el repartimiento y la saca de los infantes de Calahorra se conservan en el expediente dos reclamaciones por otros tantos soldados del contingente. A diferencia de la leva anterior los motivos de búsqueda de exención no se basan en los requisitos legales sino en motivos médicos. María de Arinzana, madre de Martín de Salvatierra alega que su hijo esta imposibilitado de un brazo, además de ser hijo único de viuda, para buscar su libertad, que logró. En el otro caso, que corresponde a Diego Revoles, es curioso por conservar el expediente un certificado medico, del doctor Pedro de Murria quien diagnostica una «enfermedad, llamada animi deliquium que vulgarmente se llama desmayo por penuria de espiritu en el coraçón [...] según la doctrina de Ypocrates", esta enfermedad de tan bello nombre, sin embargo, no le excusó de encontrase en la lista de soldados entregados.

Otro de los puntos de interés de este caso es la relación de la villa de Aldeanueva respecto a esta leva, que empieza a ocasionar problemas desde el inicio. El 9 de agosto escribe su alcalde mayor a la ciudad de Calahorra respecto a la misma «no lo pude conseguir por la mucha publicidad que a avido antes que yo recibiese el aviso de VS a cuya causa me a obligado a juntar a mis vecinos en su conzejo". En principio se hace disconformidad respecto al numero de infantes que le han correspondido, 15, «que se passe del serbizio que esta villa a acostumbrado a hacer que son doze infantes, $y$, a lo riguroso, 12 y medio". Todo ello se traduce en un tira y afloja que llega a provocar la imposición de una pena de 4.000 ducados por parte del Virrey de Navarra. Sin embargo el punto final es el acatamiento de la villa pero desligando la entrega de sus soldados de los de Calahorra tal y como pasó.

El motivo de todo lo anterior quizá no se encuentre sino en que en esos precisos momentos la villa riojana esté buscando la independencia respecto de Calahorra ${ }^{15}$.Con esta interpretación intentamos señalar que quizás el motivo de la resistencia a las ordenes reales se debe de entender como una resistencia a que sea la ciudad calagurritana la que gestione su cumplimiento.

${ }^{15}$ En el Archivo Municipal de Aldeanueva se conservan una Cédula Real de 26 de enero de 1667, en copia de 17 de junio, otorgada por D. Mariana de Austria que concede a la villa autorización para tomar un censo de 7.000 ducados sobre sus propios para ir pagando el importe de la compra de la villa (signatura 1.0.1.10) y otra de la misma mano, de fecha 31 de mayo de 1771 , en que la Reina ordena a los corregidores de Logroño, Calahorra o cualquier otro sitio a no entrometerse en tomar residencia a los justicias de la villa de Aldeanueva (signatura 1.0.1.11). 
A las dos semanas justas de la carta del Duque, el 18 de agosto de 1667 se produce el nombramiento de oficiales y la entrega de soldados al capitán Diego de Cuellar, con vestidos de munición y espadas. En el presente caso no quedan reflejados en las fuentes los datos de edad y características antropométricas de los soldados.

Una vez entregados los infantes toca arreglar las cuentas y así el 3 de septiembre se efectúa la cuenta de gastos. La leva ha costado 6.469 reales de vellón, siendo su partida más importante los 2.767 reales que importaron los vestidos y las armas. Otra vez aparece un rosario de pequeñas cantidades asociadas a oficios que han prestado servicio, como diversos correos, el alcalde, alguaciles, etc. El resto de la cantidad corresponde a soldadas y gastos de manutención de los infantes hasta su llegada a Pamplona. De esta cuenta hay que deducir 644 reales que fueron entregados voluntariamente por 5 vecinos y un zapatero forastero para contribuir a los gastos de la leva de su majestad ${ }^{16}$.

Quedan por tanto 5.825 reales pendientes de cobro, que sumados a los 587 reales del $9 \%$ del repartidor Miguel Jiménez se traducen en un repartimiento realizado el 20 de Octubre por un total de 6.516 reales, previendo quiebras, que fue lo que les costo a los vecinos esta leva de 1667.

\subsection{Leva de voluntarios. 1668}

«La reyna nuestra señora, por Real Cedula de 26 de Abril de este año ha sido servida mandarme, que, con toda brevedad, en las tres ciudades de mi corregimiento, lebante 200 hombres voluntarios para ayuda reforzar las guarniciones de las plazas de Guipúzcoa por allarse amenaçadas de franzeses y que para vestirlos socorrerlos y conducirlos se pongan, con toda promptitud a mi disposición 6.000 escudos de a 10 reales de vellon, que valen 240.000 maravedies de efectos tocantes a la Real hacienda". Así se inicia la carta del señor de Nobar de 1 de junio de 1668 a la ciudad de Calahorra donde le vuelve a pedir su colaboración.

En la ciudad de Calahorra se reúnen los regidores el 15 de junio de 1668 para dar la diligencia de aceptación de las órdenes de Nobar que transcriben. En las mismas y con detalle se hace referencia al procedimiento que se ha de seguir en la leva, en un primer lugar se establece que la misma, si bien con cargo a la Real Hacienda, se ha de hacer, con un importe señalado de doce mil reales con cargo a lo que la ciudad adeuda por el «terzero por ciento» más de esa cantidad. Por otra parte, se transcribe el procedimiento a seguir, tomado de la cedula real: «Que sea de socorrer a los soldados a razon de tres reales al día en tabla y mano propia ante el escribano de ayuntamiento de esa ciudad \{o de las otras dos referidas\}quien

${ }^{16}$ No aparecen los motivos, aparte del mero patriotismo. Sin embargo, cuando se refleja el oficio de los donantes, se tratan de un zapatero y un sastre, que quizá buscaran asegurar su participación en el negocio. 
Reclutamiento militar, articulación política y mecanismos de clase en el Alto Valle del...

también a de firmar la lista que se formare, como se haze en otras partes y rremitir copia con los nombres, filliazion y naturaleza de los soldados que se enviaren, a los oficiales del sueldo que asisten en San Sebastián para que por ella se recivan. Como se juntare la jente la podréis yr remitiendo en tropas de a cincuenta hombres o como mexor os pareciere con las guardias necesarias para su seguridad y escusar las fugas y desordenes en el camino". Termina el corregidor expresando la orden para que se inicie la leva: « $Y$ mando que con caxas y boz de pregonero se publique dicha orden y se enarbole bandera en las casas de esta ciudad y que se hagan las demás diligencias que convengan al servizio de su majestad».

\section{GRÁFICO 1. Procedencia geográfica de los soldados, 1668}

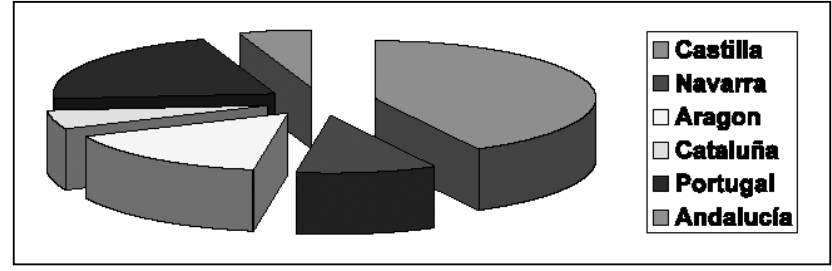

Fuente: Elaboración propia, a partir de AMC, sig. 458007, serie 2.1.5.2.

La ciudad expresa su aceptación y disposición a cumplir con el servicio debido a su majestad y así al día siguiente, 16 de junio, se produce el nombramiento de cabo de la compañía al vecino de la ciudad Antonio de Arrieta y, a partir del día 18, se empiezan a recibir los alistamientos, los cuales se hacen en los términos expresados en las ordenes recibidas, lo que incluye datos de edad y de procedencia geográfica de los reclutas, de los que destaca que ninguno de los mismos sea natural de la ciudad y que incluso los castellanos sean una minoría entre los soldados.

\section{CUADRO 4. Lista de soldados de la leva de voluntarios de 1668}

\begin{tabular}{|l|l|c|}
\hline \multicolumn{1}{|c|}{ Nombre } & \multicolumn{1}{c|}{ Origen } & Edad \\
\hline Domingo de Caparroso & Villa del Milagro. Reyno de Navarra & 24 \\
\hline Juan Gómez Albiz & Villa de Oyon? & 26 \\
\hline Francisco de Sola & Villa de Maden. Aragón. & 16 \\
\hline Bartolomé Sanchez & Ynoxossa de la Sierra & 28 \\
\hline Diego Jil & Baguena, Daroca, Aragón. & 52 \\
\hline Ignacio Fernandez de Cairedo & Caicedo en el valle de Valdivieso & 44 \\
\hline Venito de Roz & Salinas de Haro, merindad de Pamplona & 40 \\
\hline Miguel Castillo & Zaragoza, Aragón. & 26 \\
\hline Francisco Antonio de Santos & Quenca & 46 \\
\hline Joseph Zinet & Tolosa de Franzia, criado en Zaragoza & 24 \\
\hline Manuel de Salvatierra & Salvatierra, Portugal & 32 \\
\hline
\end{tabular}




\begin{tabular}{|l|l|c|}
\hline \multicolumn{1}{|c|}{ Nombre } & \multicolumn{1}{|c|}{ Origen } & Edad \\
\hline Juan de Ayala & Vitoria & 50 \\
\hline Alexandro Maestro & Andujar en Andaluzía & 42 \\
\hline Jerónimo Guijarro & Tragarete, junto a Cuenca & 28 \\
\hline Pedro del Campo & Castroburde de Campos & 38 \\
\hline Antonio Fernandez & Lisboa & 40 \\
\hline Ignacio Rodríguez & Lisboa & 18 \\
\hline Rafael Cabral & San Sebastián de Pedrera en Portugal & 26 \\
\hline Jaime Cuidor & Mencui en Cataluña & 24 \\
\hline
\end{tabular}

Fuente: Elaboración propia, a partir de AMC, sig. 458007, serie 2.1.5.2.

Muy significativo de esta recluta es el alto número de soldados con señales de heridas y quemaduras, once en total $(57,9 \%)$, que hacen pensar en un alto componente de reenganchados en esta leva.

El día 1 de julio se produce la partida hacia las plazas de Guipúzcoa, tras reunirse con un contingente que provenía de la Ciudad de Alfaro. Precisamente en este contingente alfareño se produce un episodio interesante que consiste en la enfermedad de dos de sus soldados.

Dicha enfermedad, que Jerónimo de Abadía, médico y Juan Pérez Sollarte, cirujano, diagnostican como «mal muerto, que es pegajosa y contagiosa», inicia un pequeño procedimiento en el que se toma declaración a los soldados: «fueron presos y puestos en la carcel de ella [por Alfaro] en un calabozo con el cepo y con grillos donde an estado veinte días y contra su voluntad les asentaron plaza de soldado en las compañías que se estan levantando". Suficiente para levantar sospechas sobre la voluntariedad con la que fue llevado a cabo el procedimiento, y aunque no se refleje sucesos parecidos en las fuentes respecto al caso de Calahorra, la procedencia geográfica de los infantes pueden apuntar a un uso de la recluta para buscar una paz social ${ }^{17}$, limpiando de forasteros la ciudad y evitando así el recurso a los naturales.

Por ultimo cabe señalar que se procedió, con fecha de 23 de julio de 1668 a la realización de las cuentas de gastos. Las mismas destacan por el bajo costo de la leva, 864 reales para 19 soldados, comparados con los más de 6.500 que importaron los 33 reclutados en el año anterior. En este caso no hubo repartimiento sino que, a pesar de estar realizada con cargo a la corona, no se realiza una transferencia de fondos sino que tomó la forma de un crédito fiscal con cargo a impuestos debidos.

\footnotetext{
${ }^{17}$ En este punto resulta muy interesante la lectura de ESPINO LÓPEZ, Antonio: «Recluta de Tropas y Bandolerismo durante el reinado de Carlos II: El caso de la compañía ilicitana del capitán Gaspar Irles», en Revista de Historia Moderna, $\mathrm{n}^{\circ} 24$ (2006), pp. 487-511. El autor explica la leva de compañías de bandoleros en función de un doble propósito, la mera recluta en sí y la pacificación de las comarcas donde estas gentes realizaban sus actividades. Cabe señalar además la contemporaneidad de la compañía tratada aunque sea en el ámbito de la corona de Aragón.
} 


\section{TABLAS Y GRÁFICOS}

3.1. Comparativa de los hitos mas señalados de los distintos expedientes y sus plazos.

CUADRO 5. Tiempo empleado en el reclutamiento del contingente

\begin{tabular}{|c|c|c|c|}
\hline 1644 & 1655 & 1677 & 1668 \\
\hline $\begin{array}{l}28 \text { Enero } \\
\text { Requerimiento }\end{array}$ & $\begin{array}{l}24 \text { Octubre } \\
\text { Requerimiento }\end{array}$ & $\begin{array}{l}4 \text { de Agosto } \\
\text { Requerimiento }\end{array}$ & $\begin{array}{l}1 \text { de Junio } \\
\text { Requerimiento }\end{array}$ \\
\hline $\begin{array}{l}21 \text { Marzo } \\
\text { Repartimiento }\end{array}$ & $\begin{array}{l}11 \text { Noviembre } \\
\text { Repartimiento }\end{array}$ & $\begin{array}{l}8 \text { de Agosto } \\
\text { Repartimiento }\end{array}$ & $\begin{array}{l}15 \text { de Junio } \\
\text { Reunión concejo }\end{array}$ \\
\hline $\begin{array}{l}\text { 21-28 Marzo } \\
\text { Nombramiento de } \\
\text { soldados }\end{array}$ & $\begin{array}{l}15 \text { Noviembre } \\
\text { Nombramiento de } \\
\text { soldados }\end{array}$ & $\begin{array}{l}9 \text { Agosto } \\
\text { Nombramiento de } \\
\text { soldados }\end{array}$ & \\
\hline $\begin{array}{l}31 \text { Mayo } \\
\text { Partida de los } \\
\text { soldados }\end{array}$ & $\begin{array}{l}26 \text { Noviembre. } \\
\text { Carta del Corregidor } \\
\text { de Logroño } \\
\text { agradeciendo la } \\
\text { entrega. }\end{array}$ & $\begin{array}{l}18 \text { Agosto } \\
\text { Nombramiento de } \\
\text { Capitán, alférez y } \\
\text { sargento. Entrega de } \\
\text { soldados }\end{array}$ & $\begin{array}{l}1 \text { Julio } \\
\text { Entrega de soldados }\end{array}$ \\
\hline 123 días & 32 días & 14 días & 31 días \\
\hline
\end{tabular}

Fuente: Elaboración propia, a partir de AMC, sigs. 458002, 458003, 458005 y 458007, series 2.1.5.2.

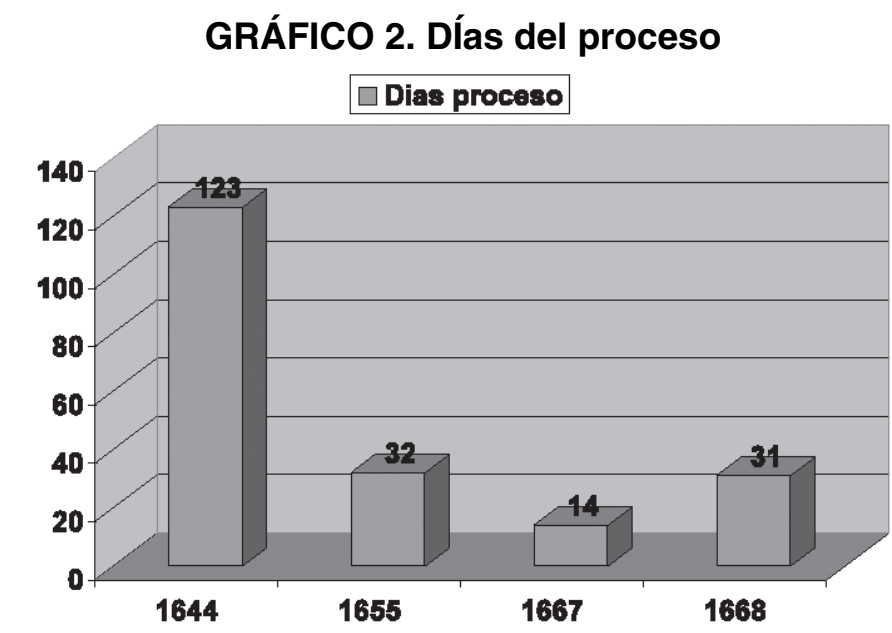

Fuente: Elaboración propia, a partir de AMC, sigs. 458002, 458003, 458005 y 458007 , series 2.1.5.2.

Este gráfico, el cual se ha obtenido con los valores de la tabla anterior es quizás el más significativo de los aquí presentados y en él se puede apreciar con toda claridad la progresiva eficacia en el reclutamiento. La curva de disminución de los tiempos es clara, aunque debe tenerse en cuenta el caso de 1655 en que no se 
conservan fuentes que daten la entrega del contingente, aunque se ha tomado la fecha del 26 de noviembre en que el Corregidor de Logroño, Joseph de Nobar, agradece la diligencia de la ciudad en el asunto. El caso de los voluntarios de 1688 es distinto ya que los formalismos del proceso, (pregón con atambores, apertura de las listas de recluta, etc.) dilatan claramente los tiempos necesarios. En cualquier caso son claros los incrementos de rapidez y eficacia del procedimiento en el periodo observado.

\subsection{Evolución de la edad de los reclutas.}

\section{GRÁFICO 3. Media de edad de los reclutas $(1664,1665$ y 1668)}

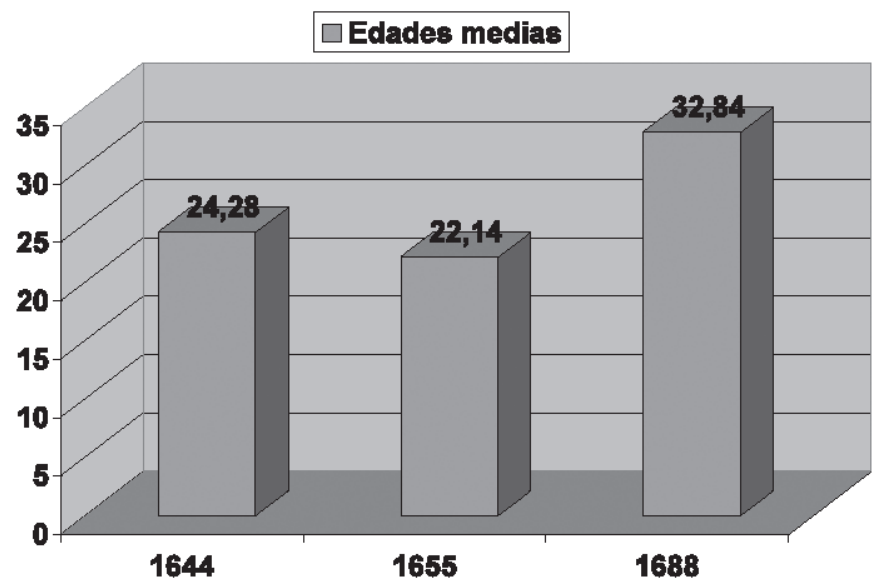

Fuente: Elaboración propia, a partir de AMC, sigs. 458002, 458003 y 458007 , series 2.1.5.2.

Aquí se recoge la edad media de los soldados de las distintas reclutas. Como se puede observar no aparece el año 1667, dado que las fuentes no recogen el dato de edad para este contingente. En el cuadro se observa una disminución de edad entre los dos primeros casos y la elevada edad de 1688, superior a los 32 años, fruto de la distinta peripecia vital de sus protagonistas, «reenganchados» en algunos casos. La disminución de edad de las primeras series puede señalar las progresivas dificultades para completar las reclutas, debiendo las autoridades incluso reclutar menores para completarlas.

\subsection{Evolución de los contingentes.}

En este cuadro se pueden observar como evoluciona el número de mozos durante los sucesivos años. Debe hacerse patente que no se deben de sacar conclusiones de una primera lectura del mismo, ya que hay que tener en cuenta que en la leva de 1655 simplemente cubre la cantidad de treinta infantes requeridos y 


\section{GRÁFICO 4. Evolución cuantitativa de los mozos reclutados}

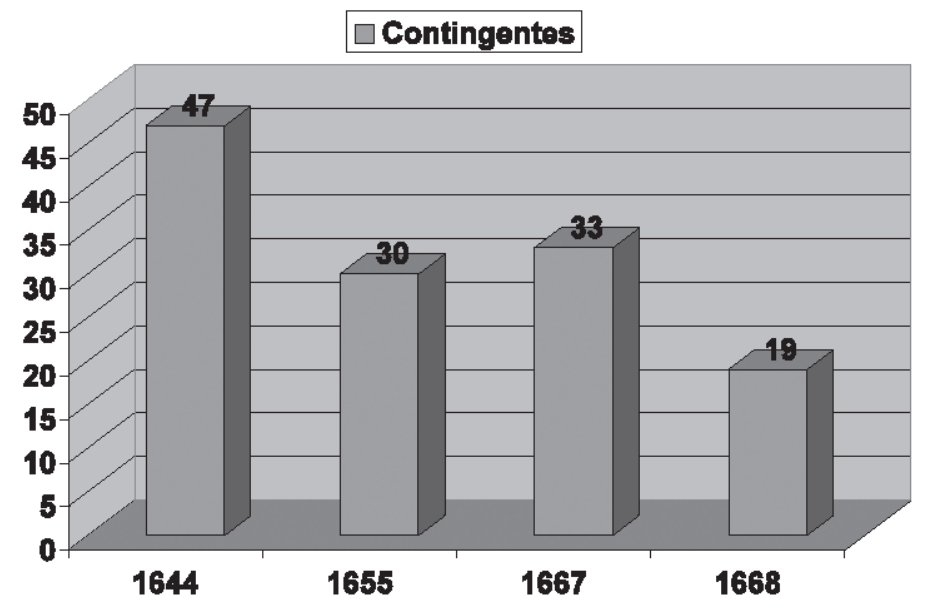

Fuente: Elaboración propia, a partir de AMC, sigs. 458002, 458003, 458005 y 458007, series 2.1.5.2.

que la de 1668 es de voluntarios. No obstante, y aunque sí pudiera parecer adivinarse un cierto descenso de los contingentes en 1667, cuyos factores explicativos podrían encontrarse en el retroceso demográfico del XVII ${ }^{18}$, lo cierto es que entre los treinta y tres soldados entregados no se encuentra el cupo de Aldeanueva, extremo ya tratado. Por tanto, y con la excepción mencionada de la leva de voluntarios, las cifras son similares y no se produce una disminución del tributo de soldados pagados.

\section{CONCLUSIONES}

El análisis de la información recabada de los expedientes permite llegar a una serie de conclusiones acerca de la relación entre la administración de la ciudad de Calahorra y su relación con los poderes centrales de la monarquía hispánica.

En un primer lugar, se parte de una situación que se puede calificar, al menos, de no idónea, ya que, durante la leva del año 1644, les resultan necesarias a las autoridades del reino repetidas instrucciones y amenazas e incluso la propia intervención real para lograr el cumplimiento de las órdenes. La dinámica de los años posteriores parece invertir esta situación y, en contraste con el debilitamiento general de la situación política y económica en que parece encontrarse el reino, supuestamente se produce un aumento progresivo de la eficacia con la que son obedecidas e implementadas las ordenes por parte de la ciudad de Calahorra, cuyo

18 Para ver la evolución demográfica de la Rioja Baja en el periodo ver LÁZARO RUIZ, Mercedes y GURRÍA GARCÍA, Pedro Antonio: La crisis de mortalidad en la Rioja (siglos XVI-XVII), Instituto de Estudios Riojanos, Logroño, 1989; y GURRÍA GARCíA, Pedro Antonio: La población de la Rioja durante el antiguo régimen demográfico, Instituto de Estudios Riojanos, Logroño, 2004. 
punto culminante sería la recluta de 1667, resuelta en dos semanas. Estas reclutas son realizadas en plazos y en número a entera satisfacción de los delegados reales quienes, en diversas ocasiones, felicitan a los regidores de la ciudad por la diligencia en el servicio a su majestad.

Y se plantea la pregunta: ¿Debemos entender que se produce un reforzamiento de la autoridad real durante el cuarto de siglo que abarcan los casos estudiados?

Para contestar esta pregunta debemos de fijarnos en la última de las reclutas. La leva de voluntarios debe de ser calificada como un fracaso en comparación con las anteriores ya que queda muy lejos de cubrir las expectativas de la Corona en cuanto a contingentes reclutados, lo que indica, como poco, que las autoridades de Calahorra no se tomaron las molestias de ocasiones anteriores. La disminución de efectivos puede tener su explicación en la voluntariedad de los infantes reclutados, pero no se debe de olvidar la otra singularidad de este procedimiento, que es su vertiente económica. En este caso la recluta se hace con dos peculiaridades: $1^{\circ} \mathrm{se}$ efectúa contra impuestos debidos por lo que supone que no puede haber repartimiento y que no se vayan a recibir fondos y $2^{\circ}$ que las cuentas son susceptibles de su intervención por la mencionada Hacienda Real, concretamente, como hemos trascrito, se encarga en las instrucciones al concejo que se remite copia de la lista a los oficiales del sueldo de San Sebastián. Todo ello limita las posibilidades de negocio que, en torno al asunto, se abren para los grupos privilegiados de la Ciudad. Quizá se explique así una cierta dejadez en las autoridades municipales calagurritanas, quienes en este caso ni tienen una motivación especial ni positiva (incentivos económicos), ni negativa (la voluntariedad de la recluta excusaría al concejo) para implicarse a fondo en la recluta.

Por tanto y respondiendo a la pregunta arriba expresada y enunciando la tesis de este trabajo, entendemos que no se produce un reforzamiento de la autoridad central sino una identificación entre los intereses de la Corona y los de grupos privilegiados de Calahorra. Esta identificación de intereses sería la que logra la efectividad en las reclutas de 1655 y 1667, cuando no se produce, cual es el caso de 1668 , la leva fracasa.

La clave está, pues, en la vertiente económica de los procedimientos. Las reclutas efectuadas supusieron una oportunidad de negocio importante para determinados grupos calagurritanos, tanto los suministros como los repartimientos arrojaban pingües beneficios, que además tenían la ventaja de fiscalizarse en el propio concejo. Esta interpretación explica y se ve reforzada por la desproporción entre los importes de la leva de voluntarios y las anteriores.

Y ¿quienes son estos grupos privilegiados?, ¿cuál es su extracción social? y, sobre todo, ¿constituían una clase social o simplemente un grupo de poder?

Las dos primeras preguntas son fáciles de responder, son básicamente los regidores y los grupos con la disponibilidad financiera que les permite el beneficiarse 
de los mecanismos descritos. Entre los mismos se encuentran miembros de la pequeña nobleza y todos en general poseen status personales prestigiosos pero no pueden identificarse, sin más, con la pertenencia a un estamento debido precisamente a la disparidad de roles desempeñados, sobre todo en el caso de los agiotistas o de los comerciantes que anticipaban género.

Para responder a la última pregunta debemos de partir de que lo evidentemente existen son estructuras sociales, entendiéndolas en línea con la sociología contemporánea como «una ordenación de personas en relaciones institucionalmente controladas o definidas ${ }^{19}$, lo que naturalmente se da. El procedimiento reglado, sus implicaciones jurídicas, sus consecuencias efectivas afirman la existencia de una estructura social concreta y definida además por relaciones de poder.

Sin embargo, tratar de elucidar el carácter estamental o clasista de dichas estructuras sería cuando menos arriesgado y además excedería claramente de los límites del presente estudio. Aunque sí sería posible cuestionar como puramente estamentales las estructuras descritas ya que, sí a las sociedades estamentales, como describía Weber, las define el honor de sus miembros en función de su estatus, precisamente el status diferenciado de los distintos elementos del grupo imposibilitaría definir las dichas estructuras como consecuencia de los estatutos jurídicos personales de los miembros que las componían.

Tampoco tenemos datos suficientes para más afirmar como determinante el elemento económico a la hora de describirlas, ya que hay componentes que se apartan de esta descripción. Lo que obstaría a su descripción como una clase ${ }^{20}$, por lo menos en el sentido marxista clásico del término.

No obstante, sí que hay algo que define a estas gentes y es su relación respecto de los mecanismos de poder y su articulación en torno a los mismos. Este poder en sí es algo concreto y efectivo, que logra reclutar unos vecinos, repartir un tributo a los ciudadanos y acaso beneficiarse económicamente del proceso. Viene al caso recordar las críticas o reformulaciones que realiza Dahrendorf ${ }^{21}$ al concepto

19 RADCLIFFE-BROWN, Alfred Reginal: Estructura y función en la sociedad primitiva, Península, Barcelona, 1972, p. 20. El autor, evidentemente, proporciona un sentido descriptivo de la función social, que tiene sus raíces en el organicismo de Spencer y que se puede oponer a la vez a la estructura piramidal marxista y al funcionalismo de Lévi-Strauss. La utilidad de la definición es evidente por su carácter concreto.

20 Aceptando el carácter estamental de la sociedad del Antiguo Régimen optamos por la expresión de mecanismos de clase por ser la que mejor ha servido al propósito del artículo. Aunque no pueda ser definida como una sociedad de clases, estimamos que se dan elementos que apuntan a su emergencia, que en tiempo histórico, está próxima al periodo estudiado. En este sentido optamos por la expresión clases sociales en un sentido operativo, ya que, en cualquier caso, una clasificación o categorización es en sí un ejercicio intelectual artificial e instrumental y sí bien es cierto que en el periodo no existe la conciencia de pertenencia a una determinada clase, lo mismo podría afirmarse, por ejemplo, de los invertebrados o las angiospermas monocotiledóneas.

21 DAHRENDORF, Ralf: Las clases sociales y su conflicto en la sociedad industrial, Rialp, Madrid, 1979 , pp. 181 y ss. El autor destaca el valor del poder frente a la propiedad como criterio de clase en base a varios argumentos: el poder es en sí una variable independiente, la propiedad no es la única for- 
de clase marxista, éste destaca el valor del poder frente al de la propiedad como criterio de clase y como fuente de conflicto social y motor de cambio.

Llegados a este punto de la argumentación podríamos afirmar, sin excesivo riesgo, que existen elementos en el sistema social referido que, primero, hacen pensar al menos en una coexistencia de elementos diversos de clase y estamentales en los sucesos tratados y segundo, lógicamente, que se trata de una situación dinámica sujeta a la evolución histórica.

Acompañando a todo lo anterior también se refleja en las fuentes la aparición de una burocracia de servicios, de pequeños y medios funcionarios (alguaciles, alcaide de la cárcel, correos, médicos, escribanos, etc.), que, según la clásica teoría de las organizaciones de Max Weber, tenderían a identificarse y a apoyar las políticas que desarrollaban.

En otro lado, existiría un amplio grupo social caracterizado por su merma de facultades políticas (los concejos pasan a ser secretos, lo que implica una perdida de representatividad de los mismos) y por las continuas exacciones en impuestos y en tributo de sangre a las que se ven sometidos.

En una interpretación final podemos afirmar que, en cierto sentido, estamos asistiendo, en un contexto de crisis, y cuando menos en el ámbito espacial estudiado, a síntomas de un cambio social con la aparición de nuevos sistemas y grupos basados en la motivación económica y no en la pertenencia a un orden estamental, apuntando a la aparición de la sociedad de clases en un momento histórico no muy alejado.

ma de dominación, las estructuras de autoridad constituyen un factor esencial en la construcción de clases y el poseer poder suele llevar aparejado otros criterios distintivos, estatus económico, prestigio, etc. 